\title{
Knowledge and Extent of Welfare and Safety Provisions of Child Protection Law in Philippines- A Case Study
}

\author{
Limbran Jay H. Ruelo ${ }^{1 \#}$, Jerald C. Moneva ${ }^{2}$ \& Clarissa D. Quesio ${ }^{3}$ \\ 1,2,3 Mandaue City, Cebu, Philippines \\ \# corresponding author \\ Type of Work: Peer-Reviewed \\ DOl: http://dx.doi.org/10.21013/jems.v16.n2.p3
}

\begin{abstract}
How to cite this paper:
Ruelo, L.J.H., Moneva, J.C., Quesio, C.D. (2020). Knowledge and Extent of Welfare and Safety Provisions of Child Protection Law in Philippines- A Case Study. IRA International Journal of Education and Multidisciplinary Studies (ISSN 2455-2526), 16(2), 102-111.

DOI: http://dx.doi.org/10.21013/jems.v16.n2.p3
\end{abstract}

(C) Institute of Research Advances.

This work is licensed under a Creative Commons Attribution-Non Commercial 4.0 International License subject to a proper citation to the publication source of the work.

Disclaimer: The scholarly papers as reviewed and published by the Institute of Research Advances (IRA) are the views and opinions of their respective authors and are not the views or opinions of the IRA. The IRA disclaims of any harm or loss caused due to the published content to any party.

Institute of Research Advances is an institutional publisher member of Publishers International Linking Association Inc. (PILA-CrossRef), USA. The institute is an institutional signatory to the Budapest Open Access Initiative, Hungary advocating the open-access of scientific and scholarly knowledge. The Institute is a registered content provider under Open Access Initiative Protocol for Metadata Harvesting (OAI-PMH).

The journal is indexed \& included in WorldCat Discovery Service (USA), CrossRef Metadata Search (USA), WorldCat (USA), OCLC (USA), Open J-Gate (India), EZB (Germany) Scilit (Switzerland), Airiti (China), Bielefeld Academic Search Engine (BASE) of Bielefeld University, Germany, PKP Index of Simon Fraser University, Canada. 


\begin{abstract}
Child protection act is all about giving protection to children who are experiencing maltreatment and abuse by their parents or someone. With knowledge about the child protection act, children can prevent the instance of child abuse and maltreatment. Protection is significant to an individual especially children. In relation to this, the study used a descriptive correlation design to know the association between the knowledge and the extent of welfare and safety of students who are involved in this study. The researchers used a checklist to collect the responses. The data collected were treated through weighted mean and chi-square. The students need to learn further on the Child Protection Act.
\end{abstract}

Keywords: Child protection, Knowledge, Children, Child rights, Safety

\title{
Introduction
}

Most of the students whether in school or a community experience being treated unjustly and even to the point of being abused at home by their parents. This can result in some students who are ill-treated in the community. Sometimes, the child's parents are unable or unwilling to protect them because of their negligence. This scenario denotes that child protection services may be needed by children at risk and need immediate and serious attention.

If people have ample knowledge and the right attitude towards child protection, it has a direct sequel on the relationship of the people towards each other. The law established the protection for the children that can help and protect the children from those abusive people. Students can avoid those abusive people if they have enough knowledge that can make them aware of their protection. People who have proper knowledge can guide those children who are abused. Child protection can keep the children safe because it requires a system that supports the development of all children as well as one that identifies a vulnerable family on behalf of at-risk children or students. Department of Social Welfare Development extends assistance to those who suffer from those abusive people.

Child protection is all about giving protection to children especially to those students in the school who suffer from violent acts [1]. While child protection acts can be integrated into school lessons, children studying it can help them to be knowledgeable enough about child protection. Similarly, people needed to know the right to guide and help those children on the right path.

\section{STATEMENT OF PURPOSE}

This study aims to assess the knowledge and extent of Welfare and Safety of students about the provisions of the law Child Protection Act. The researchers intend to administer a questionnaire related to the law to assess the knowledge of the students about the law. Further, the researchers assess the extent of welfare and safety students. Knowledge and the extent of welfare and safety of students shall be determined statistically for their association.

\section{Hypothesis}

Ho: There is no association between knowledge and extent of welfare and safety of students towards the child protection act.

H1: There is an association between knowledge of the students and the extent of welfare and safety of students towards the child protection act.

\section{REVIEW OF RELATED LITERATURE}

\section{Abuse and Protection of children}

Direct accurate exposure of a student to abuse was the most consequential determinant of the legal result in the qualitative analysis of children [2]. Many youths should be tested for their impassiveness, and the effect on their attitude and others [3]. Coincidentally, these results demonstrate the want for more 
structure and function in youth protection [4]. Many child protection agencies can benefit from parent experience about the value of establishing a different relationship as a foundation for collaboration [5]. Some beliefs affect such as parent's issues and inadequate for poor families beyond pediatrics control [6]. Neglect of the youth presents as a major factor in the health and well-being of the youth [7]. Sometimes, some children at ten years old of age are aware of the child protection mechanism [8]. To achieve positive results for youth at risk, child protection practices must be on continuous improvement, based on antidiscrimination values [9]. Recognition of children who are abused and neglected can be prevented by sufficient follow-up, family interaction, and supplication of advice, monitoring, and collaboration with agency support [10]. It would also be important to the more emotional side of the child who are victims for instance, of the culture of discrimination so that nervousness can be understood and appropriate debriefing can lead them to tell the truth [11]. Positive behavior can prevent child abuse [12]. Further, youth organizations can protect children from serious problems like child abuse [13]. Child abuse related to domestic issues can also be prevented[14]. Likewise, the consequence of child abuse can cause low selfesteem of the youth and the atmosphere of the child varies widely [15]. The creation of a law can make a definite reference to protect the child which can be possible through integration in the child's education in schools. Students' ample of knowledge about child protection act and to recognize abuse are important in child protection problems [16]. Schools can amplify the awareness of the child. Aside from this, there are instances when the performance of the child in the classroom is affected. Child protection act can contribute about the children defending themselves at times when they experience violent acts can affect problems towards learning [1].

\section{Welfare and safety}

Child protection act stipulates the provisions to ascertain the welfare and safety o the child. Different agencies working to implement the law and help the children in need. The government itself tasked the department on social welfare and services to protect the children. It is encouraged that all child protection organizations shall use structured formats, efforts, and initiatives to help out the victims in the category of abuse [18]. The organization shall include child protection services related to those bodily and sexually abused. [19]. In school, related policies directed to the youth protection are under the teacher and school authority [20]. At home, the authority is from parents though certain issues involving investigations, those families who hit their children with hard materials were more noticeable, and give their children disrespect [21]. Worse is, teachers revealed that some youths are unmindful of the child protection process mentioned and feel extemporary such as care [22]. Implantation of youth protection policies presents a level of professionalism across school organization and reduce abusive attitudes [23]. However, teachers cannot be implementing this all by themselves because of more related functions and duties especially when the case affecting the child's behavior in school is connected at home. For instance, living with their parents who used alcohol would be harmful because children put in a risk situation, and such is too domestic [24].In a wider scenario, this is quite difficult especially for children in the developing and poor countries. Understanding and learning the rights of youth are growing around the world and there is more rhetoric paid to their interest than actual compliance, especially those countries are still developed [25]. Child protection act reveals during the process of its implementation that many types of youth abuse have influence negatively on the well-being of the children [26]. The prosperous implementation of the youth welfare policy requires the engagement of many stakeholders in learning institutions [27]. In school, teachers should work based on the youth's rights which has not been developed completely [28]. Of course, teachers are not into this profession of dealing with critical matters related to child abuse. Moreover, the family and community culture sometimes impedes the implementation of a child protection act because of the fear of getting involved in legal proceedings. Teachers have not learned the appropriate means to address the needs in the implementation of child protection as well as adapted best practices to handle related scenarios. Better and specialized practices are important to facilitate diagnosis, improve reporting, reinforce cooperation with skillful, and degrade tears when dealing with youth [29]. Applicable programs and strategies shall be created for vulnerable youth [30].

Knowledge of abuse and protection is very important. This study intends to assess the youth from a harmful situation. Child protection act proves that children who experienced violence from their parents can be punished following the law. This policy motivated the youth to push their rights, it helps children to 
grow without experiencing abuse. Child protection act controls the parent to minimized in punishing their children intensively, either corporal, verbal and psychological.

\section{RESEARCH METHODOLOGY}

\section{Design}

This research study used a quantitative approach descriptive survey design to assess knowledge and extent welfare and safety of students, towards child protection act in senior high school.

\section{Environment}

The research was conducted in Jagobiao National High School located at North Road, Jagobiao, Mandaue City. Jagobiao National High School-Senior High School Department.

\section{Respondents}

The respondents of the research study are the Senior High School students from the different strands namely: General Academic Strand (GAS), Humanities and Social Sciences (HUMSS), Accountancy and Business Management (ABM), Technical, Vocational and Livelihood (TVL) and Science, Technology, Engineering and Mathematics (STEM). The researcher used complete enumeration sampling but out of 245 respondents, only 165 respondents answered willingly and voluntarily.

\section{Instrument}

The research study used a test questionnaire in gathering the data from the respondents composed of two variables. The first is for knowledge and the second is for the extent of welfare and safety of students, towards the child protection act. In the first questionnaire related to the first variable is a multiple choice type of questionnaire which is composed of 30 items. The respondents chose the best answer and their scores shall be categorized into five 1-6 (Least knowledgeable), 7-12 (Knowledgeable), 13-18 (Slightly Knowledgeable), 19-24 (Moderately Knowledgeable), 25-30 (Highly Knowledgeable). While the second part questionnaire related to the second variable is a checklist which is rating scale the choices are which is 5 (Strongly Agree), 4 (Agree), 3 (Neutral), 2 (Disagree), 1 (Strongly Disagree). The questionnaire is made up of 10 questions.1.00-1.80 (Strongly Disagree), 1.81-2.60 (Disagree), 2.61-3.40 (Uncertain), 3.41-4.20 (Agree) and 4.21-5.00 (Strongly Agree). The ratings all summed up to get a total score and clarify the level of attitude of the students towards child protection. The sum of each response from the students is also categorized.

\section{Data Gathering}

The researchers asked permission from the school head. The data are collected. During the collection, the researchers asked for the consent of the respondents to answer the questionnaire willingly. The questionnaire can be answered for at least fifteen minutes. The researchers stayed to attend to queries of the respondents, if any.

\section{Statistical Treatment}

The weighted mean was used to determine the extent of welfare and safety of students Sum of the ratings of the respondents is used to categorize the responses. Chi-square is used to treat the categories to assess the relationship between students' knowledge and extent welfare and the safety of students. 
PRESENTATION, ANALYSIS INTERPRETATION OF DATA

Table 1: Raw Scores of Students in Child protection Act Test

\begin{tabular}{|c|c|c|c|c|c|c|c|c|c|c|c|}
\hline$\#$ & Scores & $\#$ & Scores & $\#$ & Scores & $\#$ & Scores & $\#$ & Scores & $\#$ & Scores \\
\hline 1 & 20 & 33 & 18 & 65 & 12 & 97 & 10 & 128 & 16 & 160 & 19 \\
\hline 2 & 17 & 34 & 12 & 66 & 15 & 98 & 11 & 129 & 16 & 161 & 18 \\
\hline 3 & 19 & 35 & 8 & 67 & 12 & 99 & 5 & 130 & 15 & 162 & 10 \\
\hline 4 & 9 & 36 & 19 & 68 & 16 & 100 & 13 & 131 & 21 & 163 & 18 \\
\hline 5 & 10 & 37 & 21 & 69 & 12 & 101 & 9 & 132 & 18 & 164 & 22 \\
\hline 6 & 12 & 38 & 11 & 70 & 12 & 102 & 10 & 133 & 10 & 165 & 23 \\
\hline 7 & 19 & 39 & 4 & 71 & 11 & 103 & 12 & 134 & 12 & & \\
\hline 8 & 15 & 40 & 20 & 72 & 9 & 104 & 14 & 135 & 18 & & \\
\hline 9 & 10 & 41 & 20 & 73 & 14 & 105 & 10 & 136 & 15 & & \\
\hline 10 & 9 & 42 & 8 & 74 & 10 & 106 & 10 & 137 & 10 & & \\
\hline 11 & 23 & 43 & 10 & 75 & 13 & 107 & 10 & 138 & 13 & & \\
\hline 12 & 9 & 44 & 20 & 76 & 16 & 108 & 14 & $139-$ & 23 & & \\
\hline 13 & 2 & 45 & 17 & 77 & 13 & 109 & 16 & 140 & 12 & & \\
\hline 14 & 4 & 46 & 13 & 78 & 10 & 110 & 8 & 141 & 10 & & \\
\hline 15 & 5 & 47 & 10 & 79 & 14 & 111 & 10 & 142 & 19 & & \\
\hline 16 & 16 & 48 & 17 & 80 & 10 & 112 & 13 & 143 & 14 & & \\
\hline 17 & 15 & 49 & 15 & 81 & 13 & 113 & 13 & 144 & 23 & & \\
\hline 18 & 17 & 50 & 23 & 82 & 10 & 114 & 12 & 145 & 14 & & \\
\hline 19 & 19 & 51 & 13 & 83 & 21 & 115 & 16 & 146 & 22 & & \\
\hline 20 & 13 & 52 & 12 & 84 & 10 & 116 & 17 & 147 & 11 & & \\
\hline 21 & 10 & 53 & 20 & 85 & 10 & 117 & 17 & 148 & 13 & & \\
\hline 22 & 14 & 54 & 15 & 86 & 17 & 118 & 18 & 149 & 19 & & \\
\hline 23 & 17 & 55 & 18 & 87 & 10 & 119 & 15 & 150 & 12 & & \\
\hline 24 & 19 & 56 & 9 & 88 & 10 & 120 & 10 & 151 & 18 & & \\
\hline 25 & 16 & 57 & 18 & 89 & 14 & 121 & 13 & 152 & 18 & & \\
\hline 26 & 18 & 58 & 11 & 90 & 14 & 122 & 12 & 153 & 28 & & \\
\hline 27 & 18 & 59 & 4 & 91 & 13 & 123 & 16 & 154 & 16 & & \\
\hline 28 & 16 & 60 & 11 & 92 & 12 & 124 & 17 & 155 & 22 & & \\
\hline 29 & 19 & 61 & 13 & 93 & 7 & 125 & 10 & 156 & 19 & & \\
\hline 30 & 19 & 62 & 9 & 94 & 13 & 126 & 14 & 157 & 19 & & \\
\hline 31 & 15 & 63 & 9 & 95 & 11 & 127 & 10 & 158 & 23 & & \\
\hline 32 & 13 & 64 & 15 & 96 & 6 & 128 & 13 & 159 & 23 & & \\
\hline Mean & & 14.07 & & & Standard Deviation & 4.59 & & \\
\hline & & & & & & & & & & & \\
\hline
\end{tabular}

The table above shows the scores of the students who answered willingly and voluntarily. The average score of students is 14.07 with a standard deviation of 4.59 . The performance of students. Meanwhile, schools are ought to implement practices that would add more awareness of students to encourage them to participate in activities in school, such as school programs that would orient both child and parents regarding child protection. Students are vulnerable to a possible maltreatment and may form of abuse because they do not have sufficient knowledge and have less awareness of the child protection act. Assessing the knowledge of the students about the Child Protection Act is essential in policy-making and proper and maximized implementation of the law. 
Table 2: Frequency about the Level of knowledge towards child protection Act

\begin{tabular}{lcc}
\hline \multicolumn{1}{c}{ Indicators } & Frequency & Percent \\
\hline Least knowledgeable & 1 & 0.60 \\
Slightly knowledgeable & 37 & 22.4 \\
Moderately knowledgeable & 83 & 50.3 \\
knowledgeable & 44 & 26.7 \\
Total & 165 & 100.0 \\
\hline
\end{tabular}

SCALING: 1-8 (Least knowledgeable), 9-16 (Knowledgeable), 17-24 (Slightly knowledgeable), 25-30 (Moderately knowledgeable).

The table above shows the percentage of the respondents or students who are the least knowledge is $.6 \%$. Slightly knowledgeable students are $22.4 \%$, while moderately knowledgeable students are $50.3 \%$. Further, the knowledgeable students are $26.7 \%$. The researchers observed that the highest percentage is slightly knowledgeable. Students have minimal knowledge which denotes that information drive must be amplified. It is necessary that rules established the rights of children are made to the students and implemented. They can protect themselves by having ample knowledge of their rights as children or students. Children's rights which represent a unique part of human rights are intended to protect children from abuse [27]. Learning about the performance of the students in the Child Protection Act can lead to the creation of a new strategy to amplify the knowledge of the children, to protect them better, and to ensure proper child support [20].

Table 3: Extent of Welfare \& safety of students towards child protection Act

\begin{tabular}{lcc}
\hline \multicolumn{1}{c}{ Indicator } & Mean & Interpretation \\
\hline $\begin{array}{l}\text { 1. My parents can provide my basic needs. } \\
\text { 2. I haven't experienced discrimination because of my physical appearance. }\end{array}$ & 3.98 & Agree \\
& & Disagree \\
3. I did not experience any violence or abuse by my fellow students. & 3.01 & Uncertain \\
$\begin{array}{l}\text { 4. I haven't experienced things that degrades my dignity. } \\
\text { 5. I am not forced to do things that are against my will. }\end{array}$ & 3.18 & Uncertain \\
$\begin{array}{l}\text { 6. I am fully aware of my rights as a student. } \\
\text { 7. I share my knowledge about child protection to others. }\end{array}$ & 3.87 & $\begin{array}{c}\text { Agree } \\
\text { Agree }\end{array}$ \\
$\begin{array}{l}\text { 8. I feel secure that the government implemented the child protection act well. } \\
\text { 9. I believe that the government implemented the child protection act well. }\end{array}$ & 3.62 & Agree \\
10. I am glad that the government support and implemented on the child & 3.78 & Agree \\
protection act. & 3.87 & Agree \\
\hline Weighted mean & 3.54 & Agree \\
\hline
\end{tabular}

SCALING: 1.00-1.80 (Strongly Disagree), 1.81-2.60 (Disagree), 2.61-3.40 (Uncertain), 3.41-4.20 (Agree) and 4.21-5.00 (Strongly Agree)

Table 3 shows that the weighted mean is 3.54 labeled as agree to mean that the students feel about having enough knowledge about welfare, safety, and child protection. The first highest mean is the indicator, "I am glad that the government support and implemented on the child protection act." with a mean of 3.87. The government implements the protection of the children because most of the students abused by their parents. "I am fully aware of my rights as a student's" with a mean of 3.84 is the second top 
among the indicators. Children need to know their protection because they have not enough knowledge about their rights. The third highest indicator with the mean is the indicator" I believe that the government implemented the child protection act well" with a mean of 3.78. The government has created some activities to let the children know and learn their rights that can protect them. In school, the anti-bullying is related to the child protection act.

Among the indicators with lowest is mean is "I did not experience any violence or abuse by my fellow students" with a rate of 3.01. Most students who have experienced and unexperienced violence or abuse, they're following the rules and regulations in school. Some students who experienced violence or abuse, they should have to report for their safety. Second, with the lowest weighted mean is the indicator" I haven't experience discrimination because of my physical appearance" with a rate of 3.04. Discrimination can hurt someone emotionally and mentally for someone who experienced discrimination. The worst scenario for discriminated students may lead the student to depression. The last weighted mean is the indicator" I haven't experience things that degrades my dignity" with a rate of 3.18. Therefore, most of the students didn't want to degrade someone because they respect the dignity of a person. In this study, each indicator talks about the rights or protection and also the welfare and safety of the students towards the act. but some students who know their rights can prevent violence of abusive people. More work is needed to improve this child protection idea in the environment [8]. Children's rights include fair treatment, respect, and dignity of children [30].

Table 4: Frequency of the Level of Extent of Welfare and Safety of Students

\begin{tabular}{|c|c|c|}
\hline Indicators & Frequency & Percent \\
\hline Less safe \& protected & 6 & 3.6 \\
\hline Slightly safe \& protected & 61 & 37.0 \\
\hline Moderately safe and protected & 68 & 41.2 \\
\hline Safe \& protected & 30 & 18.2 \\
\hline Total & 165 & 100.0 \\
\hline
\end{tabular}

SCALING: 1-3 (Less safe \& protected), 4-6 (Slightly safe \& protected), 7-8 (Moderately safety), 9-10

(safe \& protected)

The table shows the percentage of the respondents that students who are less safe and protected are $3.6 \% .37 .0$ of them are slightly safe and protected and 41.2 are moderately safe and protected. 18.2 are safe and protected. In general, most of the respondents are moderately safe. Students are moderately knowledgeable in terms of how they know the rules and their rights accompanied by disciplined their attitude towards their welfare and safety. Partly on the belief that many young people fall into the child protection process due to insufficient support [23].Deployment of qualified school authorities to participate in child protection related programs to support the safety and well-being- of students [26].

Table 5: Knowledge and extent of welfare and safety of students towards child protection Act

\begin{tabular}{cccc}
\hline & Value & df & Asymp. Sig. (2) \\
\hline Pearson Chi-Square & $16.847^{\mathrm{a}}$ & 9 & .051 \\
No. of Valid Cases & 165 & & \\
a. 7 cells $(43.8 \%)$ have expected count less than 5. The minimum expected count is .04. & \\
\hline
\end{tabular}

The p-value is (.051) is greater than an alpha value (.05) so the null hypothesis is failed to reject therefore, there is no significant association. The student's attitude towards child protection is not affected by their 
knowledge of child protection. The researcher observed that students have not enough knowledge of their welfare and protection. Students don't have enough knowledge of their Safety so they can easily abuse by someone without taking any violence that can punish them. The differences between the right of children to take part and their right to protect [7]. The risk of harm in child protection laws admits that children do not need to be secured against demonstrable emotional or physical risk [29]. Legal and academic duty to protect children and to report abuse, as well as to fight for the rights of children [4].

\section{Summary of Findings}

The researchers also found out that having a lack of knowledge towards child protection will not increase the level of students' vulnerability. Thus, students are truly aware of child protection then it would be easy for them to determine their rights as individuals and as students.

The results show that students have slightly knowledgeable about their rights to be protected by the laws. Towards their welfare and safety, they had moderate discipline.

From the study being conducted, the research found out that there is no significant relationship between Knowledge and extent Welfare and safety of students, towards the child protection act.

\section{Conclusion}

Most students are not completely knowledgeable about welfare and safety towards the child protection act. Likewise, students are lack of awareness about the law of child protection act. Students' attitude towards child protection act can be enhanced or can be developed if they are willing to do an action against abuse of children, learning their rights can protect themselves. People in the government who have expertise in law are responsible to protect the children. Students can also follow the simple rules and regulations in school so that they can practice discipline and avoid committing an unpleasant action. Besides, students who know about learning towards child protection are safer from violations of abuse students behave accordingly but does guarantee their safety.

\section{Recommendations}

The researchers highly recommended the students to be more aware of their rights as a learner and must have enough knowledge about child protection Act. Further, students need to behave modestly and evade strangers to avoid abuses. The school must also have a program about the rights of the learners towards child protection Act. And for the community, they must have an organization that can help the students to be more knowledgeable about the child protection act. As well as the family and its members. Students should learn about child protection to expand more knowledge and understanding regarding the issue of child protection act.

\section{References:}

[1]. Kasmawati, A. (2018). Teachers under the child protection act. Journal Physics: Conference Series, 1-7doi: $10.1088 / 1742-6596 / 1028 / 1 / 012095$.

[2]. Castillo, C. (2009). Legal outcomes of sexually abused children evaluated at the Philippine general hospital child protection unit. Child Abuse \& Neglect, 33, 193-202 DOI:10.1016/j.Chiabu.2008.09.004.

[3]. Wekerle, C et.al (2009). The contribution of childhood emotional abuse to teen dating violence among child protective services-involved youth. Child Abuse \& Neglect, 3345-58 DOI: 10.1016/j.chiabu.2008.12.006'

[4]. Brown, A. (2008). Pre-service teachers' understanding of child abuse and their professional role in child protection. Child Australia, 33 (1) 25-32, https://www.researchgate/publication/256487668/Preservice_teachers'_understanding_of_child_abuse_and_t heir_professional_role_in_child_protection

[5]. Healy, K. Darlington, Y. and Feeney, J. (2011). Parents' participation in child protection practice: toward Respect and Inclusion. Families in Society: The Journal of Contemporary Social Services, 282-288 DOI:10.1606/1044-3894.4126

[6]. Bannon, M., and Carter, Y. (2003). Pediatricians and child protection: The need for effective education and training. Child Protection Training, 560-562 DOI:10.11366/adc88.7.560

[7]. Hildyard, K., and Wolfe, D. (2002). Child Neglect: developmental issues and outcomes. Child Abuse \& Neglect, 
https://scholar.google.com/scholar?hl=en\&as_sdt=0\%2C5\&q=Child+Neglect\%3A+developmental+issues+a nd+outcomes\&btnG=

[8]. Cossar, J. Brandon, ,M. and Jordan, P. (2014). You've got to trust her and she's got to trust you: Children's View on participation in the child protection, Child system. Child and Family Social Work,103-112 doi:10 $1111 / \mathrm{cfs} .12115$

[9]. Lachman, P. and Bernard, C. (2006). Moving from blame to quality: How to respond to failures in child protective services. Child Abuse \& Neglect 30, 963-986doi: 10.1610/j.chiabu.2006.07.2002

[10]. Karadag, S., Sonmez S. and Dereobali N. (2015). An investigation of preschool teacher's recognition of possible child abuse and neglect in Izmir, Turkey. Journal Interpersonal Violence, https://scholar.google.com/scholar?hl=en\&as_sdt=0\%2C5\&q=An+investigation+of+preschool+teachers+ recognition + of + possible + abuse + and + neglect $+i n+i z m i r+$ turkey $\& b t n G=$

[11]. Whittaker, A. (2011). Social defenses and organizational culture in a local authority child protection setting: challenges for the Munro review. Journal of Social Work Practice, 25 (4) 48249DOIoi:10.1080/026505533.2011.626654

[12].Poreddie, V., Gandhi, S., Kathyayani, B., \& Math, S., (2016). Nursing students' knowledge of child abuse and neglect in India. British Journal of Nursing, 25 (5) 264-268doi: 10.12968/bjon.2016.25.5.264

[13].Qaysi, N. (2018). The impact of child protection policy in Omani classrooms. International Journal of Information technology and Language Studies, 2 (1) 1-11, https://www.researchgate.net/publication/3244857886

[14].Hartley, C. (2002). The Co-occurrence of Child Maltreatment and Domestic Violence: Examining Both Neglect and Child physical Abuse. Child Maltreatment, 7 (4) 349-358 doi:10. 117766902237264.

[15]. Dahake P. \& kale, K. (2018). Impact of child abuse \& Neglect on children: A Review Article. MIDSR Journal of Dental Research, 1 (1), 36-49, https://www.researchgate.net/publication/328382549.

[16]. Yekta, M., Baherian, F. \& Nezhad, M. (2011). The attitudes of adults toward child abuse. Procedia-Social and Behavioral Sciences, 30, 278-282DOIoi: 1016/j.sbspro.2011.10.055

[17].Jud, A. Lips, U. \& landolt M. (2010). Characteristics associated with maltreatment types in children referred to a hospital protection team. Eur J Pedatr, 173-180doi: 10.1007/500431-009-1001-5.

[18]. Macmillan, H. Jamiesom, E. and Walsh, C. (2003). Reported contact with child protection services among those reporting child physical and sexual abuse: results from a survey. Child Abuse \& Neglect, 27, 13971408doi: 10.1016/j.chiabu.2003.06.003

[19].Estremera, M. (2018). The boons and banes of the child protection policy: The sorsogon west landscape. Asia $\begin{array}{lllll}\text { Pacific Journal of } & \text { Multidisciplinary } & \text { Research } & \text { (2),73-97 }\end{array}$ https://scholar.google.com/scholar?hl=en\&as_sdt=0\%2C5\&q=The+sorsogon+west+landscape\&btnG=

[20]. Trocme, N. et.al (2013). Differentiating between child protection and family support in the Canadian child welfare system's response to intimate partner violence, corporal punishment and child neglect. International Journal of Psychology, 48 (2) 128-140, https://dx.doi.org/10.1080/00207594.2013.765571

[21].Kenny, M. (2001). Child abuse reporting: Teachers' perceived deterrent. Child Abuse \& Neglect 25, 81-92. doi: 10.10016/50145-2134(00)002180.

[22].Papaefstathiou, M., Rhind, D. \& Brackenridge, C. (2012). Child protection in ballet: Experiences and views of teachers, administrators and ballet students. Child Abuse Review, doi:10.1002/car.2218.

[23]. Devaney, D. (2009). Chronic Child abuse: The characteristics and careers of the children caught in the child protection a system. British Journal of Social Work, 39, 24-45, doi:10.1093/njw/bcm089.

[24]. Okoye, U. (2011). Knowledge and awareness of the child's rights act among presidents of a university town in Enugu state, Nigeria. International Research Journals, 2 (10), 1595-1600, https//www.researchgate.net/publication/259078077.

[25]. Roche, S. (2017). Child protection and maltreatment in the Philippines: A systematic review of the literature. Asia \& Pacific Policy Studies, 4 (1) 104-128doi: 10.1002/app5/167.

[26]. Madrigal, D. V. (2018). Child protection policy compliance in catholic education institutions. Asian Journal of Education, 4 (2), 22-34

https://scholar.google.com/scholar?hl=en\&as_sdt=0,5\&q=Child+protection+policy+compliance+in+a+cathol ic+educational+institutions

[27]. Ozturk, A. and Dogan, G. (2017). Effective children's rights education from the perfectives of expert teachers in children's right education: A Turkish sample. Journal of Education and Learning, 6(4) doi:10.5539/jel.x6np303.

[28].Kraus, C. \& Jager, E. (2011), Awareness and Knowledge of child abuse among physicians - A descriptive by a sample of rural Austria. The Central European Journal of Medicine, 1-10 doi:10.1007/s00508-011-1597-2

[29].Fallon, B., Trocme N. \& Maclaurin B. (2011). Should child protection services respond differently to maltreatment, risk of maltreatment, and risk of harm. Child Abuse \& Neglect, 35 236-239doi: 10.1016/j.chiabu.2011.03.001. 
[30]. Gupta, M. \& Lata, P. (2013), Protection of child rights in India: Role of teachers and parents. Educationia Confab, https://scholar.google.com/scholar?hl=en\&as_sdt=0\%2C5\&q=protection+of+child+rights+in+india+role+of + teachers+and+parents+\&btnG= 